\title{
Response of the hydrological cycle to orbital and greenhouse gas forcing
}

\author{
V. C. Khon, ${ }^{1,2}$ W. Park, ${ }^{3}$ M. Latif, ${ }^{3}$ I. I. Mokhov, ${ }^{1}$ and B. Schneider ${ }^{2}$ \\ Received 23 June 2010; revised 25 August 2010; accepted 1 September 2010; published 14 October 2010.
}

[1] The sensitivity of the hydrological cycle to changes in orbital forcing and atmospheric greenhouse gas (GHG) concentrations is assessed using a fully coupled atmosphereocean-sea ice general circulation model (Kiel Climate Model). An orbitally-induced intensification of the summer monsoon circulation during the Holocene and Eemian drives enhanced water vapor advection into the Northern Hemisphere, thereby enhancing the rate of water vapor changes by about $30 \%$ relative to the rate given by the Clausius-Clapeyron Equation, assuming constant relative humidity. Orbitally-induced changes in hemispheric-mean precipitation are fully attributed to inter-hemispheric water vapor exchange in contrast to a GHG forced warming, where enhanced precipitation is caused by increased both the moisture advection and evaporation. When considering the future climate on millennial time scales, both forcings combined are expected to exert a strong effect. Citation: Khon, V. C., W. Park, M. Latif, I. I. Mokhov, and B. Schneider (2010), Response of the hydrological cycle to orbital and greenhouse gas forcing, Geophys. Res. Lett., 37, L19705, doi:10.1029/2010GL044377.

\section{Introduction}

[2] Paleoclimate reconstructions and model simulations reveal considerable variations of the hydrological cycle during the Holocene and Eemian, both interglacial periods, which have been mainly attributed to an intensified monsoon circulation and an associated strong water vapor transport from the oceans to the land [e.g., Rossignol-Strick, 1983; Fleitmann et al., 2003; Braconnot et al., 2008]. Global warming may become increasingly important in changing the hydrological cycle due to the exponential increase of the water-holding capacity of the atmosphere with temperature as expressed by the Clausius-Clapeyron Equation [see, e.g., Allen and Ingram, 2002; Held and Soden, 2006]. The rate of the saturation water vapor pressure change is estimated as about $6.5-7 \%$ per degree at typical temperature ranges in the troposphere [Allen and Ingram, 2002; Trenberth et al., 2003; Held and Soden, 2006]. The ratio between water vapor content and precipitation yields the residence time of water vapor in atmosphere. Present-day water vapor in the atmosphere is replenished about 40 times a year [e.g., Peixoto and Oort, 1992; Trenberth, 1998]. In a warmer climate, however, the water vapor residence time may increase [O'Gorman and

\footnotetext{
${ }^{1}$ Obukhov Institute of Atmospheric Physics, Russian Academy of Sciences, Moscow, Russia.

${ }^{2}$ Institute of Geosciences, Kiel University, Kiel, Germany.

${ }^{3}$ Leibniz Institute of Marine Sciences at Kiel University, Kiel, Germany.

Copyright 2010 by the American Geophysical Union. 0094-8276/10/2010GL044377
}

Schneider, 2008; Schneider et al., 2010] leading to a larger inertia of the atmospheric hydrological cycle.

[3] A thorough understanding of the relationship between climate changes and variations of the hydrological cycle during warm climates is needed for estimating the future hydrological changes under the influence of global warming. In the present study we use a climate model to investigate the sensitivity of the total amount and residence time of water vapor, relative humidity, precipitation and water vapor advection to temperature changes induced by changing the orbital configuration (to the Eemian, 126-115 kyr $\mathrm{BP}$; and Holocene, 9.5 kyr BP) and by increasing the concentration of GHGs according to the SRES-A1B scenario (1850-2100). Our paleo simulations are meant as a sensitivity study to explore some fundamental aspects of orbitally induced changes in the hydrological cycle, and we do not attempt to provide a fully realistic representation of the present and last interglacial.

\section{Model Experiments and Paleo-reconstructions}

[4] The Kiel Climate Model (KCM) [Park et al., 2009] consists of the atmospheric general circulation model ECHAM5 [Roeckner et al., 2003] coupled to the ocean-sea ice model NEMO [Madec, 2006]. A detailed description is given by Park et al. [2009]. Park and Latif [2008] studied the decadal and centennial variability in the Atlantic meridional overturning circulation, Latif et al. [2009] studied some aspects of KCM's response to periodic millennial solar forcing, and Khon et al. [2010] studied Northern Hemisphere sea ice changes in response to global warming.

[5] Six 1000-year long time-slice simulations were performed using different orbital configurations [Braconnot et al., 2008] corresponding to three Holocene (preindustrial, 6 and $9.5 \mathrm{kyr}$ BP) and three Eemian (115, 122 and 126 kyr BP) epochs (Table 1). The concentration of GHGs was fixed to the pre-industrial level in the paleo simulations. To account for model spin-up only the last 100 years of the simulations were analyzed. Additionally, a simulation with increasing GHG concentrations (corresponding to scenario SRES-A1B for 1850-2100) was conducted starting from the last model year of the preindustrial simulation. Reconstructions of lake level status [Viau and Gajewski, 2001] for the period $6 \mathrm{kyr}$ BP were used to evaluate the model's ability to reproduce the hydrological changes during the Holocene.

\section{Methods}

[6] Observations over the past decades indicate that changes in column integrated specific humidity (precipitable water) are similar to those in near-surface saturation water vapor pressure [Trenberth et al., 2005]. This implies an 
Table 1. Characteristics of the KCM Simulations Used in This Study and Simulated Divergence of Horizontal Atmospheric Moisture Flux $(Q)$ Through the Equator ${ }^{\mathrm{a}}$

\begin{tabular}{lccccccc}
\hline & \multicolumn{3}{c}{ Orbital Parameters } & & \multicolumn{3}{c}{ Q (mm/day) } \\
\cline { 2 - 4 } \multicolumn{1}{c}{ Period } & Eccentricity $\left({ }^{\circ}\right)$ & Obliquity $\left(^{\circ}\right)$ & $\begin{array}{c}\text { Precession } \\
\left(\omega-180^{\circ}\right)\end{array}$ & $\begin{array}{c}\mathrm{CO}_{2} \\
\text { Concentration }(\mathrm{ppm})\end{array}$ & JJA & DJF & ANN \\
\hline E126 & 0.0397 & 23.9 & 291 & 286.2 & 1.05 & -0.55 & 0.20 \\
E122 & 0.0407 & 23.2 & 356 & 286.2 & 0.90 & -0.63 & 0.12 \\
E115 & 0.0414 & 22.4 & 111 & 286.2 & 0.78 & -0.57 & 0.11 \\
H9 & 0.0194 & 24.2 & 303 & 286.2 & 0.98 & -0.57 & 0.17 \\
H6 & 0.0187 & 24.1 & 1 & 286.2 & 0.92 & -0.60 & 0.14 \\
H0 & 0.0167 & 23.4 & 102 & 286.2 & 0.87 & -0.59 & 0.13 \\
1850-2100 & 0.0167 & 23.4 & 102 & SRES-A1B & $1.12^{\mathrm{b}}$ & $-0.77^{\mathrm{b}}$ & $0.16^{\mathrm{b}}$ \\
\hline
\end{tabular}

${ }^{\text {a }}$ Positive values of $Q$ depict the northward direction.

${ }^{\mathrm{b}}$ For the period $2070-2100$.

approximately constant column integrated relative humidity $U$, defined as the ratio between precipitable water $W$ and column integrated saturation specific humidity $W^{*}: U \equiv W / W^{*}$. Therefore, we can approximate the Clausius-Clapeyron Equation [e.g., Peixoto and Oort, 1996] for the column integrated saturation specific humidity $W^{*}$ as:

$$
\frac{d \ln W^{*}}{d T}=\frac{d W}{W d T}-\frac{d U}{U d T} \approx \frac{L}{R_{v} T^{2}}
$$

where $W$ is precipitable water, $U$ column integrated relative humidity, $L$ latent heat of vaporization, $R_{v}$ the gas constant for water vapor and $T$ surface air temperature. The column integrated relative humidity $U$ was calculated using Tetens' formula [e.g., Peixoto and Oort, 1996] for saturation water vapor pressure.

[7] The global mean residence time of atmospheric moisture is estimated as the ratio of global mean precipitable water and precipitation [e.g., Trenberth, 1998; Schneider et al., 2010]. Therefore, a rate of change in the global mean resi-
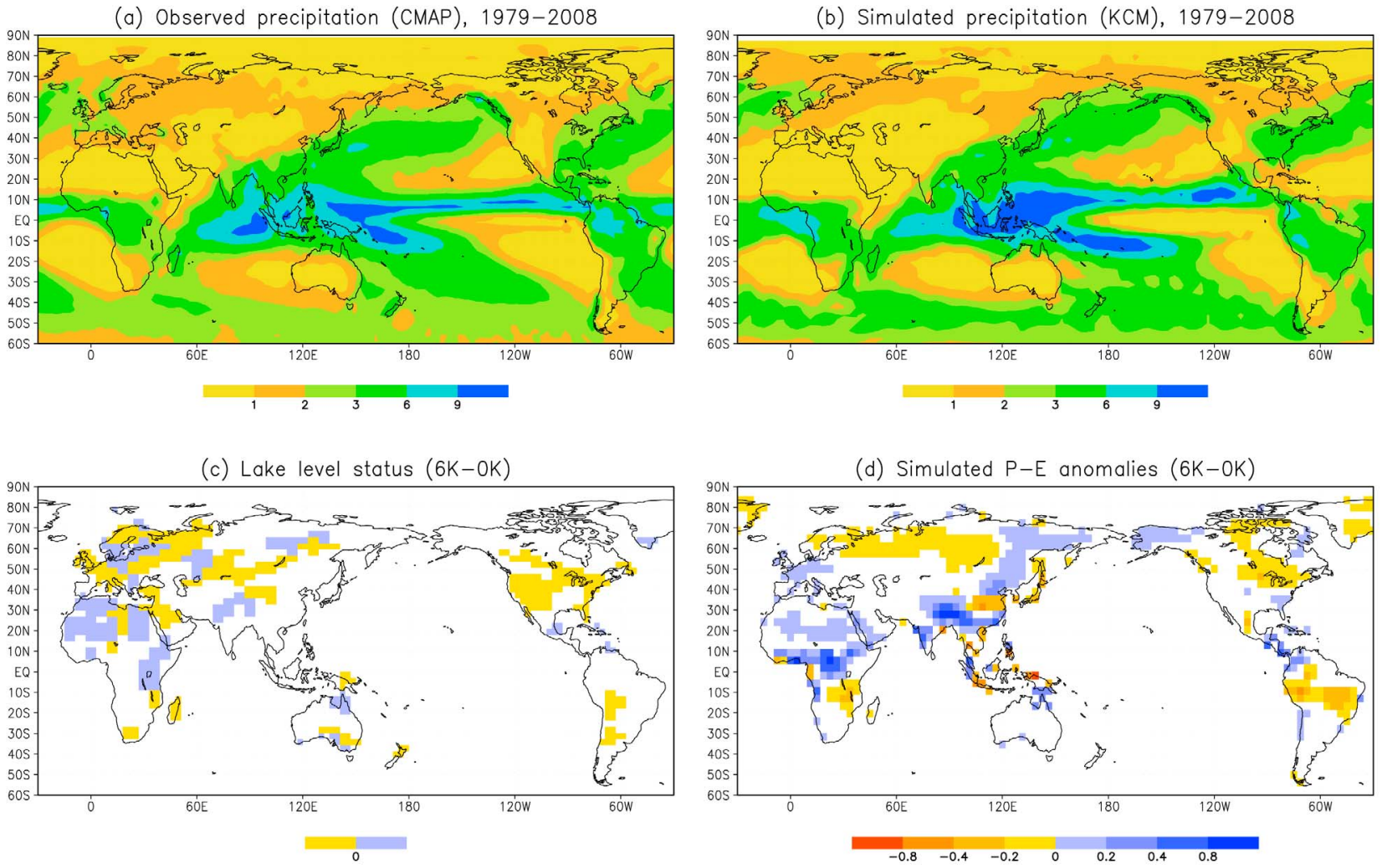

Figure 1. Annual mean precipitation (mm/day) according to (a) CMAP observations and (b) KCM simulations for the period 1979-2008. Reconstructions of (c) lake level changes for $6 \mathrm{kyr}$ BP in comparison to (d) changes in simulated precipitation minus evaporation (mm/day). Yellow and blue areas (Figure 1c) show drier and wetter conditions during midHolocene (compared to preindustrial), respectively. The model estimates (Figure 1d) are significant at the $10 \%$ level of the t-test. 

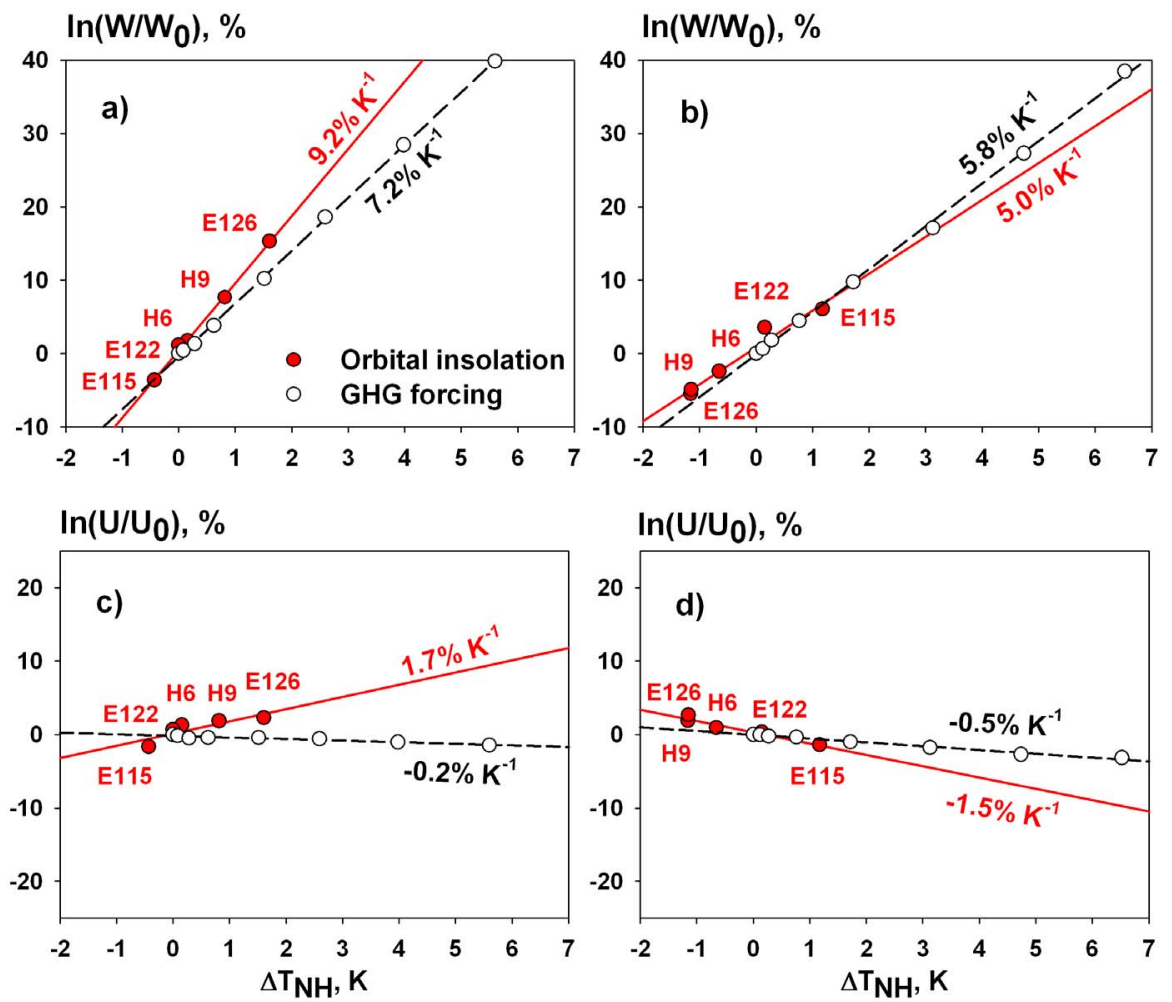

Figure 2. Percentage changes (relative to preindustrial \%) of the natural logarithm of $(a, b)$ hemispheric-mean precipitable water and $(c, d)$ vertically integrated relative humidity versus the changes in the Northern Hemisphere surface air temperature for the boreal summer (Figures $2 \mathrm{a}$ and $2 \mathrm{c}$ ) and winter (Figures $2 \mathrm{~b}$ and $2 \mathrm{~d}$ ) from the KCM simulations forced by orbital variations (red dots) and GHG emission (black dots), correspondingly. Black dots depict means for eight consequent 30-yr periods from 1861 to 2100 .

dence time with respect to surface air temperature can be estimated as the difference between the corresponding rates of precipitable water and precipitation:

$$
\frac{d(W / P)}{(W / P) d T}=\frac{d \ln (W / P)}{d T}=\frac{d W}{W d T}-\frac{d P}{P d T} .
$$

\section{Results}

[8] The KCM captures the geographical distribution of the observed modern precipitation (CMAP) [Xie and Arkin, 1997] with the better agreement over land (Figures 1a and 1b). For the mid-Holocene (Figures 1c and 1d) the model realistically reproduces the wetter conditions over northern Africa, northern India and south western China which are associated to strengthened Afro-Asian monsoon [e.g., Qin et al., 1998; Viau and Gajevsky, 2001]. The drier conditions over northern North America are also captured by the model, which can be attributed to enhanced insolation and the northward migration of the storm tracks during the mid-Holocene [e.g., Harrison, 1989].

\subsection{Sensitivity of the Hydrological Characteristics to Changes in Surface Temperature}

[9] During boreal summer, the paleo simulations show on average an exponential increase of atmospheric moisture content with surface air temperature at a rate of $9.2 \% \mathrm{~K}^{-1}$; which is $28 \%$ higher than the increase due to GHG forcing
(Figure 2a). The opposite tendency (with less significance) was found for the boreal winter (Figure 2b). According to equation (1), such a considerable deviation from the Clausius-Clapeyron rate $\left(6.5-7 \% \mathrm{~K}^{-1}\right)$ may be explained by changes in column integrated relative humidity. Under the global warming scenario the column integrated relative humidity is almost constant with a slight tendency to decrease with surface air temperature (Figures $2 c$ and $2 d$ ). Orbitally-induced warming, however, leads to an increase in relative humidity with surface air temperature (at a rate of $1.7 \% \mathrm{~K}^{-1}$ ), as shown in Figure $2 \mathrm{c}$ for the Northern Hemisphere summer.

[10] The hemispheric-mean water budget equation [e.g., Peixoto and Oort, 1992; Chen et al., 1996] for the Northern Hemisphere (e.g., during the summer or winter) can be written:

$$
(\Delta W / \Delta t)_{J J A, D J F} \approx(Q+E-P)_{J J A, D J F}
$$

where $Q$ denotes a divergence of horizontal atmospheric moisture flux through the equator (mm/day), $E$ and $P$ hemispheric-mean evaporation and precipitation $(\mathrm{mm} /$ day), $\Delta W$ the increment of the hemispheric-mean moisture storage over the season length $\Delta t$ (90 days), ( ) a seasonal average.

[11] Orbitally-induced summer warming over mid-to-high latitudes of Northern Hemisphere land areas results in an intensification of the monsoon circulation and enhanced water vapor advection to the Northern Hemisphere (Figure 3a). The 

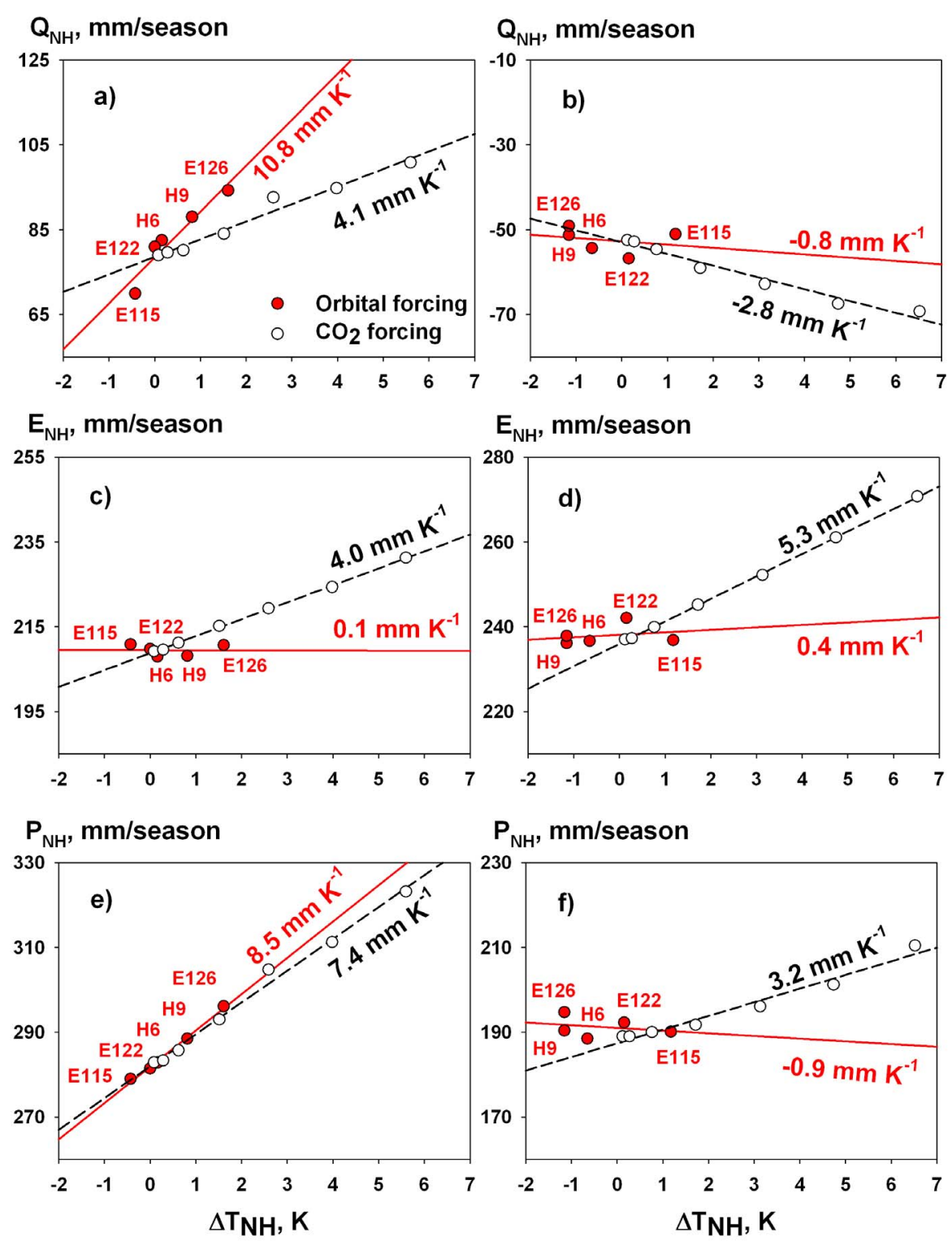

Figure 3. Changes of atmospheric moisture budget components averaged over the Northern Hemisphere: $(a, b)$ water vapor influx, (c, d) evaporation and (e, f) precipitation during boreal summer (Figures 3a, 3c, and 3e) and winter (Figures 3b, 3d, and 3f) versus the changes in surface air temperature according to simulations of KCM forced by orbital variations (red dots) and GHG emission (black dots), correspondingly. Negative values of water vapor advection depict the export of water vapor to the Southern Hemisphere.

summer atmospheric moisture advection to the Northern Hemisphere reaches its maximum during the early Holocene and early Eemian (9.5 and $126 \mathrm{kyr}$ BP) and decreases thereafter for both epochs (Table 1). The model reproduces the annual mean cross-equatorial water vapor flux of $0.13 \mathrm{~mm} /$ day for the present climate [see Chen et al., 1996]. For the 9.5 and 126 kyr BP epochs, the model simulates an increase of about $15 \%$ and $30 \%$ in annual mean atmospheric moisture inflow to the Northern Hemisphere relative to the preindustrial period (Table 1).

[12] In the global warming scenario, we find a general tendency towards higher atmospheric humidity, which leads to the higher intra-annual amplitude of cross-equatorial water vapor exchange (Table 1 and Figures $3 a$ and $3 b$ ). In the paleo simulations, the increase of summer precipitation (Figure 3e) with surface air temperature can be entirely attributed to increased water vapor transport (Figure 3a) to the Northern Hemisphere, while hemispheric-mean evaporation changes are negligible (Figure 3c). For the early Holocene and Eemian, model results show an increase in summer evaporation over monsoon regions (due to an increase in regional precipitation) and a decrease in evaporation over the tropical oceans. This reduction can be explained by the combination of a cooler ocean with reduced surface wind speed [see also Braconnot et al., 2008]. In contrast to this, the enhancement of summer precipitation over the Northern Hemisphere in the global warming scenario results from almost equivalent increases in both moisture advection and mean hemispheric evaporation (Figures 3a and 3c). For the boreal winter, the orbitally-induced increase in water vapor export from the Northern Hemisphere is less significant and balanced by 


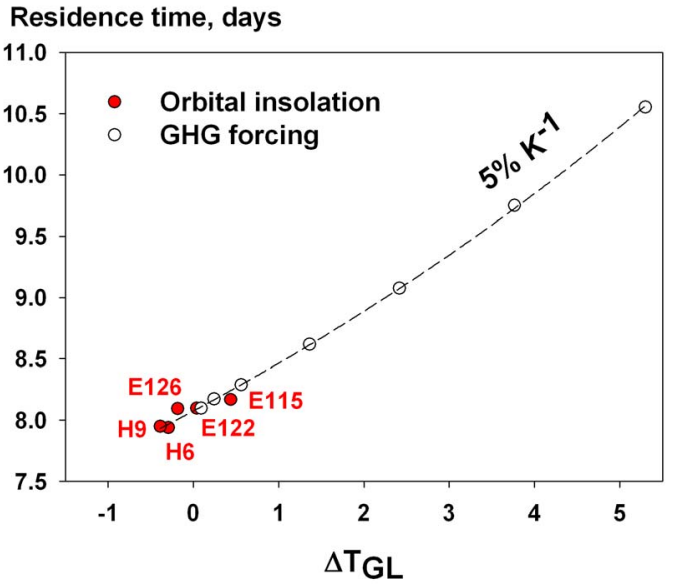

Figure 4. The annual global mean residence time of atmospheric moisture versus the global changes in surface air temperature from the KCM simulations forced by orbital variations (red dots) and GHG emission (black dots), correspondingly. Solid line depicts the rate of change in the natural logarithm of the global mean residence time $\left(5.0 \% \mathrm{~K}^{-1}\right)$.

reduced precipitation. The efficiency in converting increased horizontal moisture flux into increased hemispheric-mean vapor tendency and precipitation can be estimated as:

$$
\frac{\delta(\Delta W / \Delta t)}{\delta Q}+\frac{\delta P}{\delta Q}-\frac{\delta E}{\delta Q} \approx 1
$$

In particular, for the orbitally-forced simulations $(\delta E / \delta Q) \approx 0$ and the summer ratio of the Northern Hemisphere precipitation and vapor tendency to moisture influx constitute about $78 \%$ and $22 \%$, respectively.

[13] The inter-hemispheric exchange of atmospheric moisture is strongly related to the Hadley circulation [e.g., Oort and Yienger, 1996; Clement et al., 2004]. We find an intensification of the Hadley circulation for the early Holocene and early Eemian (in comparison to pre-industrial) which is mainly associated with the strengthening of the Southern Hemispheric Hadley cell and its deeper extension into the Northern Hemisphere during boreal summer. The orbitallyforced strengthening of the Southern Hemispheric Hadley cell constitutes about $10 \%$ and $15 \%$ for the early Holocene and early Eemian, respectively.

\subsection{Residence Time of Water Vapor in Atmosphere}

[14] The annual global mean residence time of atmospheric moisture as a function of global mean surface air temperature is shown in Figure 4. An exponential curve fits well the global residence time of water vapor for both the orbitally and GHG-forced simulations (Figure 4). For the orbitally-forced simulations, changes in hemispheric-mean precipitation are mostly due to changes in water vapor convergence (Figure 3) resulting in minor changes in globally averaged precipitation and the residence time (Figure 4). The model predicts an increase in the global mean water vapor and precipitation at rates of about $7 \% \mathrm{~K}^{-1}$ and $2 \% \mathrm{~K}^{-1}$, respectively. This implies an increase of the global residence time of water vapor in the atmosphere at a rate of about $5 \% \mathrm{~K}^{-1}$, corresponding to a $22 \%$ increase (from 9 to 11 days) in the global residence time in 2100 relative to present (Figure 4).

\section{Summary and Conclusions}

[15] According to our results, surface warming induced either by a positive northern hemisphere summer insolation anomaly (orbital) or by GHG forcing leads to a higher seasonal amplitude of the cross-equatorial water vapor exchange with stronger changes induced by the orbital parameters. The higher moisture and precipitation in summer can be fully attributed to the advection from the Southern Hemisphere, while evaporation remains largely unaffected. This effect is sufficiently strong to dominate the annual mean signal, such that the resulting precipitation increase in the Northern Hemisphere is offset by decreasing precipitation in the Southern Hemisphere. In contrast in the GHG scenario, the Northern Hemisphere moisture and precipitation increase during summer is caused equally by advection and evaporation. As a result of the stronger seasonal variations of cross-equatorial water vapor transport, the rate of change of the Northern Hemisphere precipitable water varies between $9.2 \% \mathrm{~K}^{-1}$ in summer and $5.0 \% \mathrm{~K}^{-1}$ in winter in the paleo simulations.

[16] Our results have implications for the hydrological cycle in a warmer future climate, where on millennial time scales both effects (GHG and increasing Northern Hemisphere summer insolation) are expected to combine.

[17] Acknowledgments. This work was supported by the Excellence Cluster "Future Ocean", the Sonderforschungsbereich SFB754, and the Russian Foundation for Basic Research. The model integrations were performed at the Computer Centre at Kiel University.

\section{References}

Allen, M., and W. Ingram (2002), Constraints on future changes in climate and the hydrologic cycle, Nature, 419, 224-232, doi:10.1038/nature01092. Braconnot, P., C. Marzin, L. Gregoire, E. Mosquet, and O. Marti (2008), Monsoon response to changes in Earth's orbital parameters: Comparisons between simulations of the Eemian and of the Holocene, Clim. Past, 4, 281-294, doi:10.5194/cp-4-281-2008.

Chen, T., M. Yan, J. Pfaendtner, and Y. Sud (1996), Annual variation of the global precipitable water and its maintenance: Observation and climatesimulation, Tellus, Ser. A, 48, 1-16, doi:10.1034/j.1600-0870.1996. 00001.x.

Clement, A. C., A. Hall, and A. J. Broccoli (2004), The importance of precessional signals in the tropical climate, Clim. Dyn., 22, 327-341, doi:10.1007/s00382-003-0375-8.

Fleitmann, D., S. Burns, U. Neff, A. Mangini, and A. Matter (2003), Changing moisture sources over the last 330,000 years in northern Oman from fluid-inclusion evidence in speleothems, Quat. Res., 60, 223-232, doi:10.1016/S0033-5894(03)00086-3.

Harrison, S. P. (1989), Lake levels and climatic change in eastern North America, Clim. Dyn., 3, 157-167, doi:10.1007/BF01080366.

Held, I., and B. Soden (2006), Robust response of the hydrological cycle to global warming, J. Clim., 19, 5686-5699, doi:10.1175/JCLI3990.1

Khon, V. C., I. I. Mokhov, M. Latif, V. A. Semenov, and W. Park (2010), Perspectives of Northern Sea Route and Northwest Passage in the twenty-first century, Clim. Change, 100, 757-768, doi:10.1007/ s10584-009-9683-2.

Latif, M., W. Park, H. Ding, and N. Keenlyside (2009), Internal and external North Atlantic sector variability in the Kiel Climate Model, Meteorol. Z., 18, 433-443, doi:10.1127/0941-2948/2009/0395.

Madec, G. (2006), NEMO reference manual, ocean dynamics component: NEMO-OPA. Preliminary version, Note Pole Model. 27, Inst. PierreSimon Laplace, Paris.

O'Gorman, P., and T. Schneider (2008), The hydrological cycle over a wide range of climates simulated with an idealized GCM, J. Clim., 21, 3815-3832, doi:10.1175/2007JCLI2065.1. 
Oort, A. H., and J. J. Yienger (1996), Observed interannual variability in the Hadley circulation and its connection to ENSO, J. Clim., 9, 2751-2767, doi:10.1175/1520-0442(1996)009<2751:OIVITH $>2.0 . \mathrm{CO} ; 2$.

Park, W., and M. Latif (2008), Multidecadal and multicentennial variability of the meridional overturning circulation, Geophys. Res. Lett., 35, L22703, doi:10.1029/2008GL035779.

Park, W., N. Keenlyside, M. Latif, A. Stroeh, R. Redler, E. Roeckner, and G. Madec (2009), Tropical Pacific climate and its response to global warming in the Kiel Climate Model, J. Clim., 22, 71-92, doi:10.1175/ 2008JCLI2261.1.

Peixoto, J., and A. Oort (1992), Physics of Climate, 520 pp., Am. Inst. of Phys., New York.

Peixoto, J., and A. Oort (1996), The climatology of the relative humidity in the atmosphere, J. Clim., 9, 3443-3463, doi:10.1175/1520-0442(1996) 009<3443:TCORHI $>2.0$. CO;2.

Qin, B., S. Harrison, and J. Kutzbach (1998), Evaluation of modeled regional water balance using lake status data: A comparison of 6ka simulations with the NCAR CCM, Quat. Sci. Rev., 17, 535-548, doi:10.1016/ S0277-3791(98)00011-0.

Roeckner, E., et al. (2003), The atmospheric general circulation model ECHAM 5. Part I: Model description, Rep. 349, Max Planck Inst. for Meteorol., Hamburg, Germany.

Rossignol-Strick, M. (1983), African monsoons, an immediate climate response to orbital insolation, Nature, 304, 46-49, doi:10.1038/ $304046 \mathrm{a} 0$

Schneider, T., P. O'Gorman, and X. Levine (2010), Water vapor and the dynamics of climate changes, Rev. Geophys., 48, RG3001, doi:10.1029/ 2009RG000302.
Trenberth, K. (1998), Atmospheric moisture residence times and cycling Implications for rainfall rates and climate change, Clim. Change, 39 , 667-694, doi:10.1023/A:1005319109110.

Trenberth, K., A. Dai, R. Rasmussen, and D. Parson (2003), The changing character of precipitation, Bull. Am. Meteorol. Soc., 84, 1205-1217, doi:10.1175/BAMS-84-9-1205.

Trenberth, K., J. Fasullo, and L. Smith (2005), Trends and variability in column-integrated atmospheric water vapor, Clim. Dyn., 24, 741-758, doi:10.1007/s00382-005-0017-4.

Viau, A., and K. Gajewski (2001), Holocene variations in the global hydrological cycle quantified by objective gridding of lake level databases, J. Geophys. Res., 106, 31,703-31,716, doi:10.1029/2000JD000237.

Xie, P., and P. Arkin (1997), Global precipitation: A 17-year monthly analysis based on gauge observations, satellite estimates, and numerical model outputs, Bull. Am. Meteorol. Soc., 78, 2539-2558, doi:10.1175/ 1520-0477(1997)078<2539:GPAYMA>2.0.CO;2.

V. C. Khon and I. I. Mokhov, Obukhov Institute of Atmospheric Physics, Russian Academy of Sciences, 3 Pyzhevsky, Moscow 119017, Russia. (khon@ifaran.ru)

M. Latif and W. Park, Leibniz Institute of Marine Sciences at Kiel University, Duesternbrooker Weg 20, D-24105 Kiel, Germany.

B. Schneider, Institute of Geosciences, Kiel University, Ludewig-MeynStrasse 10, D-24098 Kiel, Germany. 